\title{
Antenatal depressive symptoms and maternal health care utilisation: a population-based study of pregnant women in Ethiopia
}

Tesera Bitew ${ }^{1,2^{*}}$, Charlotte Hanlon ${ }^{1,3}$, Eskinder Kebede ${ }^{4}$, Girmay Medhin ${ }^{5}$ and Abebaw Fekadu ${ }^{1,6,7}$

\begin{abstract}
Background: Depressive symptoms during pregnancy can have multiple adverse effects on perinatal outcomes, including maternal morbidity and mortality. The potential impact of antenatal depressive symptoms on maternal health care use, however, has been little explored in low and middle-income countries (LMICs). This paper investigates whether maternal health care utilisation varies as a function of antenatal depressive symptoms.
\end{abstract}

Methods: In a population-based cross-sectional survey, 1311 women in the second or third trimesters of pregnancy were recruited in Sodo district, Gurage Zone, southern Ethiopia. Depressive symptoms were measured using a locally validated version of the Patient Health Questionnaire (PHQ-9). The association between antenatal depressive symptoms and number of antenatal care (ANC) visits was examined using Poisson regression and the association of depression symptoms with emergency health care visits using negative binomial regression. Binary logistic regression was used to investigate the association of depressive symptoms with initiation, frequency and adequacy of antenatal care.

Results: At PHQ-9 cut off of five or more, $29.5 \%$ of participants had depressive symptoms. The majority (60.5 \%) of women had attended for one or more ANC visits. Women with depressive symptoms had an increased risk of having more non-scheduled ANC visits (adjusted Risk Ratio (aRR) $=1.41,95 \% \mathrm{Cl}: 1.20,1.65)$, as well as an increased number of emergency health care visits to both traditional providers (aRR $=1.64,95 \% \mathrm{Cl}: 1.17,2.31$ ) and biomedical providers (aRR $=1.31,95 \% \mathrm{Cl}: 1.04,1.69)$ for pregnancy-related emergencies. However, antenatal depressive symptoms were not significantly associated with initiation of ANC.

Conclusions: Increased non-scheduled ANC and emergency health care visits may be indicators of undetected depression in antenatal women, and have the potential to overwhelm the capacity and resources of health care systems, particularly in LMICs. Establishment of a system for detection, referral and treatment of antenatal depression, integrated within existing antenatal care, may reduce antenatal morbidity and treatment costs and promote efficiency of the health care system.

Keywords: Maternal health care use, Antenatal care utilization, Antenatal care, Antenatal depression, Maternal depression, Sub-Saharan Africa, Ethiopia

\footnotetext{
*Correspondence: tesera_bitew@dmu.edu.et

'Department of Psychiatry, College of Health Sciences School of Medicine,

Addis Ababa University, Addis Ababa, Ethiopia

${ }^{2}$ Department of Psychology, College of Social Science and Humanities, Debre

Markos University, Debre Markos, Ethiopia

Full list of author information is available at the end of the article
} 


\section{Background}

Maternal mortality remains a major public health challenge despite the encouraging changes achieved through the Millennium Development Goals [1, 2]. Nearly $99 \%$ of global maternal deaths occur in low- and middle-income countries [1]. High maternal mortality is attributed to low antenatal health service utilization [3-7], high rates of home delivery [8-12] and low use of family planning services $[1,13]$. Ethiopia contributes to between 3 and $5 \%$ of global maternal mortality [5, 14]. Within Ethiopia, approximately three-quarters of these deaths are considered to be the result of undetected and untreated antenatal causes of obstetric complications, such as hemorrhage [15], infection [15], unsafe abortion, hypertension [15] and risk factors for obstructed labor [16-18]. To reduce the risk of pregnancy and obstetric complications, the World Health Organization recommends that women should attend at least four antenatal visits during pregnancy and deliver at a health facility [1].

In the African region, between 2000 and 2009, only $47 \%$ of births were attended by skilled personnel and only $44 \%$ of pregnant women had at least four antenatal care visits [19]. The situation is of major concern in Ethiopia [3, 4, 8, 11, 20-22], where only $11.7 \%$ of births are attended by skilled health personnel, only $34 \%$ of pregnant women attend for the recommended number of antenatal care visits [5] and there has been inadequate reduction in maternal mortality [23]. The total number of disability adjusted life years (DALYs) attributed to maternal mortality (10.6 \%) in a rural area of Ethiopia exceeded that of malaria (10.4\%), tuberculosis $(7 \%)$, depression (6.5\%) or HIV (3.5\%) [24].

Maternal mortality and morbidity are established global public health challenges, but evidence is also emerging of the public health importance of maternal depression [25-30]. Antenatal depression is estimated to affect about $20 \%$ of pregnant women in LMICs [31-35], compared to about $10 \%$ in high-income countries [36, 37]. The adverse effects of maternal depression on productivity of mothers, child growth, health and behavioral outcomes, as well as perinatal outcomes, have been well documented [38-40].

Antenatal depressive symptoms have the potential to impact negatively upon health service utilization and thereby contribute to increased perinatal complications and maternal mortality. However, studies investigating the impact of antenatal depressive symptoms on health service utilization have been small in number and conducted almost exclusively in high-income countries. In these studies, antenatal depression has been found to be associated with increased unscheduled gynecological and obstetrician visits $[25,41]$, although no association was seen with initiation of antenatal care visits [42]. In studies examining the adequacy of antenatal care utilization, defined as attendance for $50 \%$ or more of the expected ANC reviews [41, 43], no association was found between antenatal depression and adequate use of ANC. In the only study from Africa that the authors are aware of, a non-significant association was found between antenatal depression and antenatal care attendance [44].

There is, therefore, a clear gap in understanding the impact of depressive symptoms on antenatal care use, particularly in LMICs where perinatal outcomes are poor. Improved detection and treatment of antenatal depression is not prioritized in most LMIC health systems [45] but may improve ANC use, and therefore obstetric outcomes. Indeed, better evidence is needed to support greater priority to mental health care. In this paper, we report findings from a study that aimed to investigate whether antenatal depressive symptoms are associated with initiation, frequency and adequacy of ANC visits, and adherence with recommended schedules of ANC visits, in a rural Ethiopian setting. We hypothesised that ANC utilisation would vary as a function of antenatal depressive symptoms.

\section{Methods}

The study was a cross-sectional, population-based survey.

\section{Study setting}

The study was conducted in the Sodo District, Gurage Zone, Southern Nations, Nationalities and People's Region (SNNPR) of Ethiopia, located about $100 \mathrm{~km}$ from the capital, Addis Ababa. The district is administratively divided into 58 kebeles or sub-districts (54 rural and four urban), the smallest administrative unit in Ethiopia. Sodo has a varied topography (40\% plains, $7 \%$ mountainous, $30 \%$ undulating and $23 \%$ valleys) and agriculture is the main mode of subsistence in the area (Tafesse, 2002, personal communication). The population of the district was estimated to be 161,952 persons $(79,356$ men; 82,596 women) in 2007 [46]. The majority of the inhabitants belong to the Sodo Gurage ethnic group ( $85 \%$ ) $[47,48]$. The remaining population are mostly Oromo and Amhara in ethnicity [48]. The official language of the region and the district is Amharic.

\section{Sample size estimation and recruitment of participants}

A total of 1311 women were recruited into the study between September and November 2014. Eligibility criteria for women were as follows: (1) in the second or third trimester of pregnancy; (2) continuous residence in the area for at least the preceding 6 months; (3) not having hearing or cognitive impairment to the extent of impairing capacity to communicate adequately, and (4) giving informed consent to take part in the study.

EpiInfo version 7 software (EpiInfo; CDC, 2000) was used to estimate the sample size assuming a statistical 
power of $80 \%$ with a two tailed $5 \%$ margin of error for three dependent variables (ANC use, delivery care use and pregnancy complications). ANC utilization as the dependent variable yielded the greatest sample size: 276 women with depressive symptoms, the exposure or independent variable, assuming $34 \%$ antenatal care utilization [5] among the unexposed and a $6 \%$ difference between exposed and unexposed groups. To obtain 276 pregnant women with antenatal depressive symptoms, assuming a prevalence of $19.9 \%$ [32], 1387 pregnant women needed to be screened for depression.

\section{Locating participants}

In the Ethiopian health system, community-based health workers (Health Extension Workers; HEWs) are responsible for health prevention and promotion activities. HEWs collect community-based data for the health information system, especially information about maternal health. During their 3-monthly house-to-house visits of the population living in their sub-district, they are expected to identify and monitor pregnant mothers and to keep accurate and up-to-date maternal records in the health posts (primary care facilities at the sub-district level). In addition, the health development army (a community-based network of health education volunteers, each of whom covers five families) are required to report pregnant women in their respective units to the HEWs. For this study, HEWs, health development army leaders, community leaders and pregnant women themselves acted as key informants to identify all pregnant women living in their sub-district. The data collectors then carried out home visits to the identified pregnant women, gave them information about the study, obtained informed consent and then conducted the interview. Women were visited three times before they were considered unavailable to participate in the study.

\section{Data collection and quality control}

There were 40 data collectors and four supervisors, all of whom had previous experience of data collection for other projects in the same district. The data collectors were trained for 2 days by the main study co-ordinator (TB) on administration of the instruments, the objectives of the study and ethical issues. Lectures, demonstrations and role plays were the methods used to train the data collectors. The main coordinator of the study also held weekly meetings with the data collectors and supervisors. The conduct of the study was closely monitored and supervised. Completed questionnaires were checked carefully on a daily basis for consistency, adherence to instructions and missing data, first by the supervisors, then by main coordinator and finally by the data entry clerks. Questionnaires deemed to have problems were returned back to the data collectors for investigation, and if necessary for correction or reassessment. Finally, data were computerized using a double data entry with EpiData version 3.1 (EpiData; CDC, 2000).

\section{Measurement \\ Outcomes}

Utilisation of ANC services was assessed in relation to four dimensions of antenatal care: initiation of antenatal care (i.e., time of the first ANC visit), frequency of ANC attendance, adequacy of ANC attendance and adherence to ANC schedules.

Initiation of ANC and frequency of ANC attendance were assessed by an item in a self-report questionnaire asking about the gestational age at which the women attended for each of their ANC visits. Any ANC initiated before or at the 16th week of gestation was labeled as "timely initiation" and visits after this time were labeled "late" based on WHO recommendations. Adherence to ANC attendance schedules was estimated in relation to WHO guidance, which proposes that the first ANC attendance should take place before the 16th week of gestation; second ANC attendance between weeks 24 and 28; third ANC between weeks 30 and 32; and fourth ANC visit between weeks 36 and 40. Any visits out of these proposed intervals were considered to be nonscheduled. Women who initiated ANC visits between 24 and 28 weeks of gestation and continued the remaining visits as recommended were considered to be non-adherent for the first ANC schedules but adherent for the remaining ANC schedules. Finally, the numbers of scheduled and non-scheduled ANC visits were counted for each respondent. Respondents were asked about the number of emergency contacts for pregnancy complications with a range of specified types of traditional healers or biomedical health service providers available in the area [49].

The frequency of antenatal care visits was expressed as the ratio of the number of actual ANC visits to the total number of ANC visits recommended by WHO at the given gestational age. WHO proposes one, two, three and four ANC contacts for women at the 16th, 28th, 32nd and 40th week of gestation, respectively. Finally a ratio of $125 \%$ or more of the recommended number of ANC visits was categorized as "increased use of ANC" and otherwise as "expected use of ANC". Adequacy of ANC use was also categorized based on Kotlchuk's index [50]. Women with $50 \%$ or more ANC attendance and timely initiation (during or before the 16th week of gestation), as defined by WHO, were described as receiving "adequate ANC" while those with either late initiation or less than a $50 \%$ expected attendance of ANC were defined as receiving "inadequate ANC". 


\section{Exposure}

Antenatal depressive symptoms were assessed with a locally validated Amharic version of the Patient Health Questionnaire (PHQ-9) [51]. A score of five or more was considered to be indicative of high antenatal depressive symptoms (the optimal score for increased probability of major depressive disorder in the criterion validation study). In Ethiopia, the PHQ-9 was found to have good internal consistency (Cronbach's alpha $=0.81$ ) and excellent intra-class correlation of 0.92 in a study of 926 outpatients in a major referral hospital in Addis Ababa [52]. Measures of depression specific to the perinatal period were considered; however, a validation study in rural Ethiopia concluded that Edinburgh Postnatal Depression Scale had low criterion validity and poor internal consistency [53]. Although previous Ethiopian studies had used the locallyvalidated Self-Reporting Questionnaire (SRQ-20) for measurement of common mental disorders [34], the PHQ-9 was preferred due to its focus on depressive symptoms [53].

\section{Potential confounders}

Intimate partner violence (IPV) was assessed using a five item scale, the Women's Abuse Screening Test (WAST) $[54,55]$. The scale was chosen for its brevity and the acceptability of the wording. Social support was measured using the Oslo Social Support Scale (OSSS-3) [56], a three item scale which asks about concern from others, ease of getting help and the number of supporting persons that participants can count on. Stressful life events were measured with the list of threatening experiences (LTE), a 12-item self-report questionnaire. The LTE has good testretest reliability and internal consistency [57]. Both the OSSS-3 and LTE have been used in a community based study in the same setting [47].

Respondents were asked about the number of previous stillbirths, miscarriages, neonatal and infant mortality. The items were adapted from the Ethiopian Demographic Health Survey of 2011 [5]. Women were also asked whether they had chronic medical conditions, including HIV, tuberculosis, renal or cardiac diseases, hypertension, anemia or gastritis. Items asking the number of emergency health care provider visits to biomedical and traditional health care providers were used to assess women's emergency health care use for pregnancy-related complications.

An item from the Ethiopian Demographic Health Survey was used to ask whether the woman wanted the pregnancy (labeled as "wanted") or would have preferred it to happen at a future date (labeled as "mistimed") or if she had never wanted to be pregnant at all (labeled as "unwanted"). Accessibility of health care was measured by using seven items asking respondents about the level of difficulty and distance to reach the nearest health facility and travel time to their respective nearest health facility, as well as affordability and availability of health care facilities [58]. Finally, self-reported pregnancy complications included a list of key danger signs during pregnancy, including bleeding, swollen hands/face, blurred vision, convulsions, high fever, loss of consciousness, severe abdominal pain, premature rupture of membranes, and discharge with unusual odor, pain during urination, severe headache and severe weakness. Closed ended questions were used to assess socio-demographic and socio-economic variables, including residence, marital status, estimated monthly income and educational level of participants.

\section{Data analysis}

Data were analysed using the Statistical Packages for Social Sciences, version 20 (SPSS 20; IBM Corp 2012) and Stata version 13 (Stata Corp, 2013). A total of eight missing data [PHQ (1 missing), IPV (3 missing), accessibility to health care facility (3 missing) and LTE (1 missing)] were found. We included an average of observed scores of a respective variable to fill the missed item in the variables. Residence was categorized into urban/rural; marital status into married and single (never married, divorced and widowed) categories; Educational level into "non-literate", "primary schooling (Grade 1-8)" and "Secondary Schooling" (Grade 9 and above) categories. Monthly income was categorized into tertiles as "high", "medium", and "low". The profile of predictors and outcomes was described using simple descriptive summary values.

Poisson regression was used to examine the association between antenatal depressive symptoms and components of antenatal care use (number of non-scheduled and total number of ANC visits) after testing the assumption of equality of the variance and the mean. Negative binomial regression was used to examine the association between antenatal depressive symptoms and number of traditional and biomedical emergency health care provider visits. Socio-demographic and socioeconomic variables, interpersonal and life adversities, obstetric and medical conditions were included in all analyses as potential confounders. Gestational age was controlled as an offset variable in all poisson and negative binomial regression models. Binary logistic regression was used to test the relation between antenatal depressive symptoms and frequency, adequacy and initiation of antenatal health care use.

\section{Results}

Amongst 1321 women identified as potentially eligible, 44 were excluded because they were in the first trimester of pregnancy; three refused participation and seven couldn't be accessed despite three trials to find from their location. 


\section{Characteristics of participants}

Among study participants $98.6 \%$ were married, $67.0 \%$ were non-literate, and $92.1 \%$ were rural residents. The mean age was 26.8 years (Table 1 ). With respect to ANC attendance, $60.5 \%$ had initiated ANC ( $37.0 \%$ by 16 weeks gestation). About one third of women fulfilled criteria for adequate antenatal care. Nearly $30.0 \%$ of women had PHQ-9 score of five or more, indicating probable depression. Forty four percent of the participants reported an unintended pregnancy (36.2 \% unwanted and $7.8 \%$ mistimed) and $27.0 \%$ had a history of adverse perinatal outcomes during their previous pregnancy.
Antenatal depressive symptoms and adherence to ANC visits Depressive symptoms during pregnancy were associated significantly with increased risk of having more nonscheduled ANC visits (aRR = 1.41, $95 \%$ CI: $1.20,1.65)$ and an increased number of total ANC visits ( $\mathrm{aRR}=1.23,95 \%$ CI: 1.12, 1.36) (Table 2).

Greater accessibility of the primary health care facility was associated with increased risk of having more nonscheduled ANC visits (aRR $=1.0695 \%$ CI: 1.02, 1.09) as well as with an increased number of total ANC visits $(\mathrm{aRR}=1.04,1.02,1.06)$. Similarly, women with experience of ANC use in the past pregnancy had increased risk of more non-scheduled ANC visits $(\mathrm{aRR}=1.28$,

Table 1 Characteristic of respondents $(N=1311)$

\begin{tabular}{|c|c|c|c|}
\hline Characteristics & Values & Number & Percent \\
\hline \multirow[t]{2}{*}{ Marital Status } & ${ }^{{ }^{c} \text { Single }}$ & 18 & 1.4 \\
\hline & Married & 1293 & 98.6 \\
\hline \multirow[t]{3}{*}{ Pregnancy Intention } & Unwanted & 475 & 36.2 \\
\hline & Mistimed & 102 & 7.8 \\
\hline & Wanted & 734 & 56.0 \\
\hline \multirow[t]{3}{*}{ Monthly Income category } & High & 429 & 32.7 \\
\hline & Medium & 423 & 32.3 \\
\hline & Low & 459 & 35.0 \\
\hline \multirow[t]{2}{*}{ Residence } & Rural & 1208 & 92.1 \\
\hline & Urban & 103 & 7.9 \\
\hline \multirow[t]{3}{*}{ Mother's Education } & Grade $9-12$ and above & 53 & 4.0 \\
\hline & Grade 1-8 & 380 & 29.0 \\
\hline & Non-literate & 878 & 67.0 \\
\hline \multirow[t]{2}{*}{ Patient Health Questionnaire Status } & $\mathrm{PHQ} \geq 5$ & 387 & 29.5 \\
\hline & $\mathrm{PHQ}<5$ & 924 & 70.5 \\
\hline \multirow[t]{2}{*}{ Use of ANC during Past Pregnancy } & Yes & 793 & 60.5 \\
\hline & No & 518 & 39.5 \\
\hline \multirow[t]{2}{*}{ Number of Chronic Illnesses } & One or more & 440 & 33.6 \\
\hline & None & 871 & 66.4 \\
\hline \multirow[t]{2}{*}{ Past experience of adverse perinatal outcomes } & 1 or more & 356 & 27.2 \\
\hline & None & 955 & 72.8 \\
\hline \multirow[t]{2}{*}{ Number of ANC Visits } & Never initiated ANC & 461 & 35.2 \\
\hline & Once or more & 850 & 64.8 \\
\hline \multirow[t]{2}{*}{ Self-reported pregnancy complications } & None & 655 & 50.1 \\
\hline & One or more & 656 & 49.9 \\
\hline \multirow[t]{2}{*}{ Adequacy of Antenatal Care } & anadequate & 861 & 65.7 \\
\hline & bAdequate & 450 & 34.3 \\
\hline \multirow[t]{2}{*}{ Time of Initiation of ANC } & Timely (Up to 16th week of gestation) & 455 & 37.7 \\
\hline & Late (After 16th week of gestation) & 856 & 62.3 \\
\hline
\end{tabular}

Mean age $=26.8$ years

${ }^{\mathrm{a}}$ Inadequate $=$ less than $50 \%$ of expected ANC attendance or late initiation

${ }^{\mathrm{b}}$ Adequate $=$ more than $50 \%$ of expected ANC attendance and timely initiation

'Unmarried, divorced, widowed 
Table 2 The association of antenatal depression with total and non-scheduled number of ANC visits

\begin{tabular}{|c|c|c|c|c|c|}
\hline \multirow[t]{2}{*}{ Characteristics } & & \multicolumn{2}{|c|}{ Total number of ANC Visits } & \multicolumn{2}{|c|}{ Number of Non-scheduled ANC visits } \\
\hline & & CRR (95 \% Cl) & ARR $(95 \% \mathrm{Cl})$ & CRR $(95 \% \mathrm{Cl})$ & ARR $(95 \% \mathrm{Cl})$ \\
\hline \multirow[t]{2}{*}{ Antenatal Depression: } & PHQ-9 $\geq 5$ & $1.12(1.02,1.23)^{a}$ & $1.23(1.12,1.36)^{b}$ & $1.21(1.04,1.40)^{a}$ & $1.41(1.20,1.65)^{\mathrm{b}}$ \\
\hline & $\mathrm{PHQ}-9<5$ & 1 & 1 & 1 & 1 \\
\hline \multicolumn{2}{|c|}{ Accessibility of Health facility } & $1.06(1.03,1.09)^{\mathrm{a}}$ & $1.04(1.02,1.06)^{b}$ & $1.09(1.04,1.23)^{b}$ & $1.06(1.02,1.09)^{\mathrm{b}}$ \\
\hline \multirow[t]{2}{*}{ Marital Status: } & Single & $1.03(0.72,1.47)$ & $0.99(0.69,1.42)$ & $1.13(0.60,2.15)$ & $1.04(0.59,1.82)$ \\
\hline & Married & 1 & 1 & 1 & 1 \\
\hline \multirow[t]{2}{*}{ Residence: } & Rural & $0.65(0.51,0.83)^{\mathrm{a}}$ & $0.85(0.72,1.01)$ & $0.50(0.40,0.61)^{b}$ & $0.65(0.51,0.85)^{b}$ \\
\hline & Urban & 1 & 1 & 1 & 1 \\
\hline \multirow[t]{3}{*}{ Income: } & High & $1.15(0.97,1.37)$ & $1.13(1.00,1.26)^{\mathrm{a}}$ & $1.37(1.11,1.70)^{\mathrm{a}}$ & $1.29(1.07,1.56)^{a}$ \\
\hline & Medium & $1.06(0.89,1.26)$ & $1.03(0.92,1.15)$ & $1.13(0.89,1.43)$ & $1.05(0.88,1.26)$ \\
\hline & Low & 1 & 1 & 1 & 1 \\
\hline \multirow[t]{3}{*}{ Education: } & Grade $9-12$ and above & $1.79(1.28,2.50)^{b}$ & $1.16(0.92(1.48)$ & $2.06(1.52,2.81)^{b}$ & $0.99(0.69,1.43)$ \\
\hline & Grade 1-8 & $1.27(0.90,1.49)$ & $1.08(0.96,1.20)$ & $1.13(0.89,1.43)$ & $1.10(0.92,1.32)$ \\
\hline & Non-literate & 1 & 1 & 1 & 1 \\
\hline \multicolumn{2}{|c|}{ Intimate Partner Violence } & $1.01(0.98,1.03)$ & $1.01(0.99,1.03)$ & $1.00(0.97,1.03)$ & $1.00(0.97,1.02)$ \\
\hline \multicolumn{2}{|l|}{ Social Support } & $1.02(0.99,1.06)$ & $1.02(1.00,1.04)$ & $1.03(0.99,1.08)$ & $1.03(0.99,1.07)$ \\
\hline \multicolumn{2}{|c|}{ Number of Life threatening Events } & $1.01(0.96,1.06)$ & $1.01(0.98,1.04)$ & $1.05(0.98,1.17)$ & $1.05(1.00,1.10)$ \\
\hline \multicolumn{2}{|l|}{ Parity } & $0.93(0.90,0.96)^{b}$ & $0.94(0.92,0.97)^{b}$ & $0.89(0.85,0.94)^{b}$ & $0.91(0.86,0.95)^{b}$ \\
\hline \multirow[t]{3}{*}{ Pregnancy Intention: } & Unwanted & $0.75(0.65,0.88)^{b}$ & $0.84(0.75,0.93)^{b}$ & $0.75(0.61,0.91)^{\mathrm{a}}$ & $0.89(0.75,1.06)$ \\
\hline & Mistimed & $0.89(0.68,1.17)$ & $0.91(0.77,1.09)$ & $0.78(0.56,1.10)$ & $0.86(0.64,1.15)$ \\
\hline & Wanted & 1 & 1 & 1 & 1 \\
\hline \multicolumn{2}{|c|}{ Adverse Perinatal outcomes: $\geq 1^{c}$} & $0.90(0.77,1.06)$ & $0.94(0.84,1.04)$ & $0.79(0.64,0.97)^{a}$ & $0.85(0.71,1.02)$ \\
\hline \multicolumn{2}{|c|}{ ANC visit in past pregnancy: $\geq 1^{c}$} & $1.08(0.94,1.25)$ & $1.19(1.08,1.31)^{b}$ & $1.10(0.91,1.33)$ & $1.28(1.09,1.51)^{\mathrm{a}}$ \\
\hline \multicolumn{2}{|c|}{ Chronic Medical conditions: $\geq 1^{c}$} & $1.08(0.94,1.25)$ & $1.07(0.97,1.17)$ & $1.14(0.95,1.37)$ & $1.10(0.95,1.28)$ \\
\hline
\end{tabular}

${ }^{\mathrm{a}}$ Statistically significant at $<0.05$

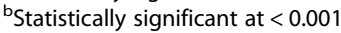

"Reference group was "none"

$95 \%$ CI: $1.09,1.51$ ) as well as total number of ANC visits $(\mathrm{aRR}=1.19,95 \% \mathrm{CI}: 1.08,1.31)$ compared to those without experience of ANC use. Each increment in parity was associated with reduced risk of non-scheduled ANC visits ( $\mathrm{aRR}=0.91,95 \% \mathrm{CI}: 0.86,0.95)$ and a lower total number of ANC visits ( $\mathrm{aRR}=0.94,95 \% \mathrm{CI}$ : 0.92, 0.97). Rural residence and low income were associated with reduced levels of non-scheduled ANC visits.

\section{Antenatal depressive symptoms and initiation, frequency and adequacy of ANC use}

Antenatal depressive symptoms were associated with increased odds of ANC attendance beyond that recommended in ANC schedules $(\mathrm{aOR}=1.86,95 \% \mathrm{CI}: 1.29$, $2.68)$. Increased access to the health facility $(\mathrm{aOR}=1.16$, $95 \%$ CI: 1.07, 1.25) and experience of ANC in a previous pregnancy $(\mathrm{aOR}=1.65,95 \% \mathrm{CI}, 1.14,2.41)$ were associated with increased ANC visits. Increasing parity $(\mathrm{aOR}=0.84,95 \% \mathrm{CI}: 0.75,0.94)$ was associated with lower than expected ANC attendance. Increased parity
$(\mathrm{aOR}=0.90,95 \% \mathrm{CI}: 0.83,0.96)$ and unwanted pregnancy $(\mathrm{aOR}=0.63,95 \% \mathrm{CI}: 0.48,0.83)$ were associated with lower levels of adequate ANC care (Table 3).

Antenatal depressive symptoms were not associated with timely initiation of $\mathrm{ANC}$ visits $(\mathrm{aOR}=1.24,95 \%$ CI: $0.95,1.63$ ) (Table 3). Increased accessibility of the health facility $(\mathrm{aOR}=1.07,95 \% \mathrm{CI}: 1.02,1.13)$ and having one or more chronic conditions $(\mathrm{aOR}=1.28$, $95 \%$ CI: 1.00, 1.62) were associated significantly with increased timely initiation of ANC. Increased parity $(\mathrm{aOR}=0.99,95 \% \mathrm{CI}: 0.83,0.96)$ and unwanted pregnancy $(\mathrm{aOR}=0.65,95 \% \mathrm{CI}: 0.49,0.86)$ were associated significantly with delayed initiation of ANC.

\section{Antenatal depressive symptoms and emergency health care use}

Antenatal depressive symptoms were associated with increased risk of a greater number of traditional emergency health care provider visits $(\mathrm{aRR}=1.64,95 \% \mathrm{CI}$ : $1.17,2.31)$, biomedical health care provider visits $(\mathrm{aRR}=$ 
Table 3 The association of antenatal depression with initiation of ANC, frequency of ANC follow ups and adequacy of ANC

\begin{tabular}{|c|c|c|c|c|c|c|c|}
\hline \multirow{2}{*}{\multicolumn{2}{|c|}{ Characterstics }} & \multicolumn{2}{|l|}{ Initiation of ANC } & \multicolumn{2}{|c|}{$\begin{array}{l}\text { ANC Visits higher than expected in a } \\
\text { given Gestational Age }\end{array}$} & \multicolumn{2}{|c|}{ Adequacy of ANC Use } \\
\hline & & COR $(95 \% \mathrm{Cl})$ & AOR $(95 \% \mathrm{Cl})$ & COR $(95 \% \mathrm{Cl})$ & AOR $(95 \% \mathrm{Cl})$ & COR $(95 \% \mathrm{Cl})$ & AOR $(95 \% \mathrm{Cl})$ \\
\hline \multirow{2}{*}{\multicolumn{2}{|c|}{ PHQ 9 Score: PHQ-9 $\geq 5$}} & $1.10(0.93,1.24)$ & $1.24(0.95,1.63)$ & $1.45(1.05,2.05)^{a}$ & $1.86(1.29,2.68)^{a}$ & $1.09(0.0 .85,1.39)$ & $1.24(0.94,1.62)$ \\
\hline & & 1 & 1 & 1 & 1 & 1 & 1 \\
\hline \multicolumn{2}{|l|}{ Access to Healthcare } & $1.10(1.04,1.15)^{b}$ & $1.07(1.02,1.13)^{\mathrm{a}}$ & $1.18(1.10,1.27)^{b}$ & $1.16(1.07,1.25)^{b}$ & $1.10(1.04,1.15)^{b}$ & $1.07(1.02,1.13)^{\mathrm{a}}$ \\
\hline \multirow[t]{2}{*}{ Marital Status: } & Married & $1.20(0.46,3.12)$ & $1.26(0.47,3.39)$ & $1.31(0.38,4.58)$ & $1.08(0.29,3.98)$ & $0.96(0.36,2.56)$ & $1.03(0.37,2.86)$ \\
\hline & Single & 1 & 1 & 1 & 1 & 1 & 1 \\
\hline \multicolumn{2}{|l|}{ Residence: Rural } & $0.47(0.31,0.70)^{b}$ & $0.80(0.48,1.32)$ & $0.39(0.24,0.62)^{b}$ & $0.62(0.34,1.14)$ & $0.48(0.32,0.72)^{b}$ & $0.82(0.49,1.36)$ \\
\hline \multirow[t]{3}{*}{ Income: } & High & $1.14(0.87,1.51)$ & $1.08(0.80,1.47)$ & $1.19(0.81,1.75)$ & $1.18(0.77,1.820)$ & $1.16(0.88,1.54)$ & $1.09(0.80,1.48)$ \\
\hline & Medium & $1.11(0.84,1.46)$ & $1.05(0.78,1.40)$ & $1.05(0.71,1.57)$ & $0.97(0.64,1.47)$ & $1.11(0.84,1.47)$ & $1.04(0.78,1.40)$ \\
\hline & Low & 1 & 1 & 1 & 1 & 1 & 1 \\
\hline \multirow[t]{3}{*}{ Education: } & Non-literate & $0.32(0.18,0.57)^{b}$ & $0.64(0.32,1.26)$ & $0.39(0.20,0.76)^{a}$ & $1.06(0.45,2.50)$ & $0.32(0.18,0.56)^{b}$ & $0.59(0.29,1.20)$ \\
\hline & $\begin{array}{l}\text { Elementary } \\
\text { Schooling }\end{array}$ & $0.46(0.26,0.82)^{a}$ & $0.61(0.30,1.23)$ & $0.60(0.30,1.19)$ & $1.10(0.49,2.47)$ & $0.44(0.25,0.79)^{a}$ & $0.61(0.31,1.20)$ \\
\hline & $\begin{array}{l}\text { Secondary } \\
\text { Schooling }\end{array}$ & 1 & 1 & 1 & 1 & 1 & 1 \\
\hline \multicolumn{2}{|c|}{ Intimate Partner Violence } & $1.01(0.97,1.05)$ & $1.02(0.97,1.06)$ & $1.03(0.99,1.07)$ & $1.02(0.96,1.08)$ & $1.00(0.97,1.04)$ & $1.01(1.00,1.06)$ \\
\hline \multicolumn{2}{|l|}{ Social Support } & $1.04(0.98,1.10)$ & $1.03(0.97,1.10)$ & $1.00(0.93,1.09)$ & $1.00(0.92,1.09)$ & $1.04(0.98,1.04)$ & $1.04(0.97,1.11)$ \\
\hline \multicolumn{2}{|c|}{ Number of Life Threatening Events } & $1.04(0.96,1.13)$ & $1.04(0.95,1.14)$ & $1.04(0.94,1.16)$ & $1.02(.91,1.16)$ & $1.04(0.96,1.07)$ & $1.04(0.95,1.14)$ \\
\hline \multicolumn{2}{|l|}{ Parity } & $0.87(0.82,0.92)^{b}$ & $0.89(0.83,0.96)^{a}$ & $0.84(0.77,0.91)^{b}$ & $0.84(0.75,0.94)^{a}$ & $0.87(0.82,0.92)^{b}$ & $0.90(0.83,0.96)^{a}$ \\
\hline \multirow[t]{3}{*}{ Pregnancy Intention: } & Unwanted & $0.54(0.42,0.69)^{b}$ & $0.65(0.49,0.86)^{a}$ & $0.62(0.43,0.88)^{a}$ & $0.78(0.52,1.15)$ & $0.52(0.40,0.67)^{b}$ & $0.63(0.48,0.83)^{\mathrm{a}}$ \\
\hline & Mistimed & $1.03(0.67,1.59)$ & $1.11(0.71,1.71)$ & $0.80(0.43,1.49)$ & $0.84(0.44,1.60)$ & $1.04(0.68,1.59)$ & $1.11(0.72,1.72)$ \\
\hline & Wanted & 1 & 1 & 1 & 1 & 1 & 1 \\
\hline \multicolumn{2}{|c|}{ Previous Use of ANC: $\geq 1^{c}$} & $1.01(0.80,1.28)$ & $1.14(0.88,1.47)$ & $1.24(0.89,1.74)$ & $1.65(1.14,2.41)^{a}$ & $1.04(0.82,1.31)$ & $1.18(0.91,1.52)$ \\
\hline \multicolumn{2}{|c|}{ Past Adverse obstetric history: $\geq 1^{c}$} & $0.98(0.76,1.26)$ & $1.08(0.82,1.43)$ & $0.72(0.49,1.06)$ & $0.74(0.49,1.12)$ & $0.96(0.74,1.24)$ & $1.06(0.80,1.41)$ \\
\hline \multicolumn{2}{|c|}{ Chronic Medical conditions: $\geq 1^{c}$} & ${ }^{a} 1.30(1.03,1.64)$ & $1.28(1.00,1.62)^{\mathrm{a}}$ & $1.06(0.77,1.47)$ & $1.03(0.73,1.45)$ & $1.30(1.03,1.63)^{\mathrm{a}}$ & $1.27(1.00,1.62)$ \\
\hline
\end{tabular}

${ }^{a}$ Statistically significant at $<0.05$

${ }^{\text {bStatistically significant at }<0.001}$

"Reference was "none"

$1.32,95 \% \mathrm{CI}: 1.04,1.69)$ and increased number of total emergency health care visits $(\mathrm{aRR}=1.44,95 \% \mathrm{CI}: 1.16$, 1.80) (Table 4).

Having a chronic medical condition and higher income were associated with increased emergency health care visits of any type (traditional, biomedical and total number of health care visits). Increased number of traditional emergency health care provider visits was associated with rural residence $(\mathrm{aRR}=3.87,95 \% \mathrm{CI}: 1.54$, 9.74), being in a high income category ( $\mathrm{aRR}=4.40,95 \%$ CI: $2.89,6.69)$ and medium income categories $(\mathrm{aRR}=$ 1.07, 95 \% CI: 1.26, 3.08), increased intimate partner violence $(\mathrm{aRR}=1.15,95 \% \mathrm{CI}: 1.09,1.21)$, increased number of threatening life events $(\mathrm{aRR}=1.27,95 \% \mathrm{CI}$ : 1.16, 1.39) and having one or more chronic medical conditions $(\mathrm{aRR}=2.86,95 \% \mathrm{CI}: 0.03,4.03)$. A history of adverse perinatal outcomes was associated with a lower risk of traditional health care visits $(\mathrm{aRR}=0.53,95 \% \mathrm{CI}$ : $0.36,0.80)$ but not associated with emergency help- seeking from biomedical health care providers $(\mathrm{aRR}=$ 1.05, 95 \% CI: 0.81, 1.37) (Table 4).

An increased number of biomedical health care provider visits was also associated with increased access to health care facility ( $\mathrm{aRR}=1.3495 \% \mathrm{CI}: 1.00,1.79)$, high income ( $\mathrm{aRR}=1.46,95 \% \mathrm{CI}: 1.15,1.84$ ) and having one or more chronic medical conditions $(\mathrm{aRR}=1.11$, $95 \%$ CI: $1.06,1.17)$ as shown in Table 4.

\section{Discussion}

In this community-based survey from rural Ethiopia, nearly one-third of antenatal women had high levels of depressive symptoms. Antenatal depressive symptoms were associated independently with increased number of non-scheduled ANC visits, and increased presentations for emergency health care. There was no association between antenatal depressive symptoms and initiation and adequacy of ANC. 
Table 4 The association of antenatal depression and Number of traditional, modern and total number of emergency health care provider visits during pregnancy

\begin{tabular}{|c|c|c|c|c|c|c|c|}
\hline \multirow[t]{2}{*}{ Characteristics } & & \multicolumn{2}{|c|}{$\begin{array}{l}\text { Number of Traditional health } \\
\text { care provider visits }\end{array}$} & \multicolumn{2}{|c|}{$\begin{array}{l}\text { Number of Modern health } \\
\text { care provider visits }\end{array}$} & \multicolumn{2}{|c|}{$\begin{array}{l}\text { Number of either of both } \\
\text { health care provider visits }\end{array}$} \\
\hline & & CRR $(95 \%$ Cl) & aRR $(95 \% \mathrm{Cl})$ & cOR $(95 \%$ Cl) & aRR $(95 \% \mathrm{Cl})$ & cOR $(95 \%$ Cl) & aRR (95 \% Cl) \\
\hline \multirow[t]{2}{*}{ PHQ 9 Score: } & $P H Q \geq 5$ & $2.15(1.70,2.71)^{b}$ & $1.64(1.17,2.31)^{a}$ & $1.29(1.03,1.62)^{a}$ & $1.32(1.04,1.69)^{a}$ & $1.63(1.33,1.99)^{b}$ & $1.44(1.16,1.80)^{a}$ \\
\hline & $\mathrm{PHQ}<5$ & 1 & 1 & 1 & 1 & 1 & 1 \\
\hline \multicolumn{2}{|l|}{ Access to Healthcare } & $0.94(0.89,0.98)^{a}$ & $1.07(1.00,1.14)$ & $1.10(1.06,1.17)^{b}$ & $1.11(1.06,1.17)^{b}$ & $1.04(1.00,1.08)$ & $1.08(1.03,1.13)^{a}$ \\
\hline \multirow[t]{2}{*}{ Marital Status: } & Single & $0.19(0.03,1.37)$ & $0.13(0.01,1.26)$ & $1.17(0.50,2.74)$ & $1.33(0.56,3.17)$ & $0.75(0.32,1.72)$ & $0.84(0.35,1.97)$ \\
\hline & Married & 1 & 1 & 1 & 1 & 1 & 1 \\
\hline \multirow[t]{2}{*}{ Residence: } & Rural & $1.47(0.86,2.51)$ & $3.87(1.54,9.74)^{a}$ & $060(0.40,0.92)^{a}$ & $0.79(0.46,1.34)$ & $0.96(0.71,1.29)$ & $1.17(0.70,1.95)$ \\
\hline & Rural & 1 & 1.00 & 1 & 1.00 & 1 & 1.00 \\
\hline \multirow[t]{3}{*}{ Income: } & High & $4.44\left(3.33,5.93^{\mathrm{a}}\right.$ & $4.40(2.89,6.69)^{b}$ & $1.52(1.15,1.99)^{\mathrm{a}}$ & $1.34(1.00,1.79)^{\mathrm{a}}$ & $2.20(1.72,2.82)$ & $1.93(1.48,2.51)^{b}$ \\
\hline & Medium & $1.35(0.95,1.91)$ & $1.97(1.26,3.08)^{a}$ & $1.00(0.76,1.32)$ & $0.98(0.74,1.30)$ & $1.11(0.87,1.43)$ & $1.18(0.91,1.5)$ \\
\hline & Poor & 1 & 1 & 1 & 1 & 1 & 1 \\
\hline \multirow[t]{3}{*}{ Education: } & $\begin{array}{l}\text { Secondary } \\
\text { Schooling }\end{array}$ & $0.98(0.52,1.84)$ & $0.81(0.25,2.66)$ & $1.50(0.832 .71)$ & $0.96(0.45,2.06)$ & $1.27(0.73,2.20)$ & $0.92(0.45,1.88)$ \\
\hline & $\begin{array}{l}\text { Elementary } \\
\text { Schooling }\end{array}$ & $0.92(0.72,1.78)$ & $1.07(0.68,1.7)$ & $0.85(0.66,1.10)$ & $0.86(0.63,1.16)$ & $0.96(0.77,1.20)$ & $0.96(0.73,1.28)$ \\
\hline & Non-literate & 1 & 1 & 1 & 1 & 1 & 1 \\
\hline \multicolumn{2}{|c|}{ Intimate Partner Violence } & $1.13(1.10,1.16)^{b}$ & $1.15(1.09,1.21)^{\mathrm{b}}$ & $1.00(0.96,1.04)$ & $0.99(0.95,1.03)$ & $1.07(1.04,1.11)^{\mathrm{b}}$ & $1.05(1.02,1.09)^{\mathrm{a}}$ \\
\hline \multicolumn{2}{|l|}{ Social Support } & $0.96(0.91,1.01)$ & $1.00(0.92,1.09)$ & $1.04(0.99,1.10)$ & $1.05(0.99,1.12)$ & $1.01(0.96,1.06)$ & $1.03(0.97,1.09)$ \\
\hline \multicolumn{2}{|c|}{ Number of Life Threatening Events } & $1.30(1.25,1.350)^{b}$ & $1.27(1.16,1.39)^{b}$ & $1.10(1.02,1.17)^{a}$ & $1.07(1.00,1.16)$ & $1.16(1.09,1.23)^{b}$ & $1.10(1.03,1.18)^{a}$ \\
\hline \multicolumn{2}{|c|}{ Parity } & $1.17(1.11,1.23)^{b}$ & $1.04(0.94,1.14)$ & $1.04(0.99,1.10)$ & $1.03(0.95,1.11)$ & $1.07(1.03,1.13)^{b}$ & $1.04(0.98,1.11)$ \\
\hline \multirow[t]{3}{*}{ Pregnancy Intention: } & Unwanted & $1.94(1.53,2.451)^{b}$ & $1.26(0.86,1.85)$ & $0.95(0.75,1.21)$ & $0.94(0.72,1.23)$ & $1.17(0.95,1.44)$ & $0.97(0.76,1.24)$ \\
\hline & Mistimed & $1.18(0.76,1.84)$ & $0.72(0.39,1.34)$ & $0.97(0.64,1.47)$ & $0.98(0.63,1.51)$ & $0.99(0.68,1.44)$ & $0.89(0.60,1.32)$ \\
\hline & Wanted & 1 & 1 & 1 & 1 & 1 & 1 \\
\hline \multicolumn{2}{|c|}{ Past Adverse obstetric history: Yes $^{c}$} & $0.71(0.55,0.92)^{a}$ & $0.53(0.36,0.80)^{a}$ & $1.10(0.86,1.40)$ & $1.05(0.81,1.37)$ & $0.97(0.78,1.21)$ & $0.89(0.70,1.14)$ \\
\hline \multicolumn{2}{|c|}{ Chronic Medical conditions: Yes ${ }^{c}$} & $3.51(2.73,4.51)^{\mathrm{b}}$ & $2.86(2.03,4.03)^{b}$ & $1.58(1.26,1.98)^{\mathrm{a}}$ & $1.46(1.15,1.84)^{b}$ & $2.14(1.75,2.63)^{b}$ & $1.84(1.49,2.28)^{\mathrm{b}}$ \\
\hline
\end{tabular}

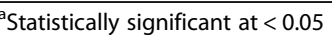

${ }^{\mathrm{b}}$ Statistically significant at $<0.001$

"Reference was "none"

\section{Prevalence of antenatal depressive symptoms}

The prevalence of depressive symptom s among antenatal women varies across LMIC studies. Our finding of a relatively high prevalence of depressive symptoms (29.5\%) during pregnancy accorded with studies from South Africa [59], Ghana [31], Viet Nam [33] and south Brazil [60] where the prevalence of antenatal depression was 39, 26, 29.9 and $32.8 \%$, respectively. However, the prevalence of antenatal depressive symptoms in this study was higher than that seen in previous community studies from Ethiopia. In a study from south-western Ethiopia [32], which used the Edinburgh Postnatal Depression Scale (not validated for a rural Ethiopian population) the prevalence of antenatal depression was found to be $19.9 \%$. However, in a study in Butajira (a district on the southern border of Sodo) the prevalence of depressive and anxiety symptoms measured with the validated Self Reporting Questionnaire (SRQ-20) was found to be $12.0 \%$ [34]. Normal symptoms of pregnancy which overlap with depressive symptoms in PHQ-9 may explain the relatively high prevalence of antenatal depressive symptoms in our study. Nonetheless, we have also noted the importance of somatic symptoms in the presentation of perinatal depression in this population [30]. Despite these variations, depressive symptoms in the perinatal period are important public health issues in LMICs, with the potential to affect not only health and functioning but also service use.

\section{Antenatal depression and ANC attendance}

Our finding of increased non-scheduled ANC visits and total number of ANC visits in women with antenatal depressive symptoms were broadly consistent with the few reports from high income countries [25, 41, 61]. Increased non-scheduled ANC visits in our study is also in keeping with meta-analyses and systematic reviews of 
depression in general, where depression was associated with around a three times increase in non-adherence to medical recommendations [62, 63]. The increased nonscheduled ANC visits among women with depressive symptoms may be explained by somatic symptoms of depression motivating them to seek help. Our finding of an increased number of total ANC visits among women with depressive symptoms was mainly through nonscheduled ANC visits. The increased number of ANC visits among women with higher socio-economic status is in keeping with a study from Ghana [64].

\section{Antenatal depressive symptoms vs initiation and adequacy of ANC use}

In the current study, antenatal depressive symptoms were not associated significantly with initiation of ANC visits in either univariate or multivariable models. This differs from the finding of delayed initiation of ANC in depressed women in the USA [42]. Timely initiation of ANC for some women might have preceded the onset of depressive symptoms since we recruited women in the second and third trimesters and consequently screened depressive symptoms after 16th week of gestation (a cut off time point of timely or delayed initiation of ANC) for most women. This might be the reason for the non-significant finding of the association between antenatal depressive symptoms and initiation of ANC in our study.

Antenatal depressive symptoms were associated with a higher overall number ANC visits than expected but non-significantly associated with adequacy of antenatal care visits after adjusting for potential confounders. The study replicated the non-significant association of antenatal depression and adequacy of antenatal health care visits in hospital based studies from the USA [41, 43].

\section{Antenatal depressive symptoms and emergency health care use}

The finding of a significant association between antenatal depressive symptoms and number of emergency visits to traditional and biomedical health care provider visits is in keeping with hospital-based studies in Australia [65], Sweden [25] and the USA [41]. In those countries, antenatal depressive symptoms were associated with increased obstetrician visits and increased use of planned Caesarean section [25, 41].

Various explanations have been provided to understand increased emergency health care provider visits. First, reduced self-care [63], social support [66] and reduced cognition and motivation $[67,68]$ among people with depressive symptoms increase their vulnerability to other medical conditions and complications that consequently increase the chance of needing emergency intervention [63]. Second, women with depressive symptoms may delay timely help-seeking due to reduced social support [66], lower satisfaction with health care services [65], poorer motivation and memory of schedules $[67,68]$ and reduced self-care [63] which means that the condition is more likely to progress and lead to presentation as an emergency. Third, women with depression may worry more about perinatal symptoms [69-71] so that they seek emergency care. This has been reported previously in postnatal women in HICs, in which emergency healthcare utilization may be increased substantially, including visits to psychiatrists, paediatricians, general practitioners and traditional providers [65, 72].

Although selection bias was minimized in this population based study, recall bias is an important issue because of low literacy and poor record keeping in this predominantly rural population. Nevertheless, by conducting the study in the antenatal period, the risk of recall bias is reduced especially for measurement of the outcome variables. The risk of social desirability bias was minimized by training the data collectors so that they would clearly explain about the study and its objective to the participants before conducting interview, encouraging them to be frank in their responses. Though we used robust method to identify all cases during the study period, we cannot be certain whether all pregnant women in the district have been identified. Furthermore, we assessed women's adherence to WHO's recommendations on ANC attendance but not the adherence of health professionals to WHO's recommendations to ANC.

\section{Conclusions}

This study offers an insight to health planners about the potential effects of antenatal depressive symptoms on antenatal service utilization. Our finding of a strong association between antenatal depressive symptoms and use of ANC services, mostly through non-scheduled visits, is important, given the relatively high prevalence of depressive symptoms in this population. First, the limited service available for antenatal women could be overwhelmed. Secondly, the increase in non-scheduled visits could potentially be associated with undetected and untreated pregnancy complications as a result of inadequate antenatal care. Thirdly, depressive symptoms are associated with an increase in medically unexplained somatic complaints [63,73], which may result in increased non-scheduled visits. Thus, establishing a system for improved detection, referral and treatments of antenatal depression may promote efficiency in the health system and may potentially reduce morbidity, mortality and cost.

\section{Abbreviations}

ANC: Antenatal care; ANDS: Antenatal depressive symptoms; aOR: adjusted Odds Ratio; aRR: adjusted Risk Ratio; ARR: Adjusted Risk Ratio; Cl: Confidence Interval; CRR: Crude Risk Ratio; GA: Gestational age; LMIC: Low and middle income countries; LMP: Last Menstrual period 


\section{Acknowledgment}

We thank Dr. Simone Honikman for commenting on an earlier draft of the manuscript and Professor Martin Prince, Professor Larry Wissow and Dr Rosie Mayston for their comments during the inception and design of the study. We would also like to acknowledge the Sodo District Health Bureau for their technical and administrative support. We would like to thank PRIME for the financial support. Finally, we would like to thank all of the participants of this study for their time and patience in responding to our interviews.

\section{Funding}

The study was funded by the Department for International Development (UKAID) (PO 5248). This particular study was supported through the small grant's initiative of the Programme for Improving Mental health care (PRIME) provided to TB. However, the funding body did not play any role in the design of study, data collection, interpretation of data or in writing or submission of the manuscript.

\section{Availability of data and materials}

The datasets generated and analysed during the current study are not publicly available at present. (1) Data were collected as part of a crosscountry study and will be available for further cross-country work; (2) This was also part of a PhD project and the student needs to use the data for his PhD work before data could be made available; (3) We have not received consent from participants to share the data on the web but, will be available from the corresponding author on reasonable request.

\section{Authors' contributions}

$\mathrm{TB}, \mathrm{CH}, \mathrm{EK}$ and $\mathrm{AF}$ were involved in designing the study. $\mathrm{TB}, \mathrm{CH}$ and $\mathrm{AF}$ participated in data collection. TB, CH, GM and AF participated in analysis. TB prepared first draft. TB, CH, EK, GM and AF revised drafts of the paper. TB, $\mathrm{CH}, \mathrm{GM}, \mathrm{AF}$ read and approved the final manuscript.

\section{Authors' information}

TB: PhD fellow, Addis Ababa University, College of Health Sciences, Department of Psychiatry; Lecturer in Debre Markos University, College of Social Science and Humanities, Department of Psychology.

$\mathrm{CH}$ : Associate Professor of Psychiatry (MD, PhD, MRCPsych), Addis Ababa University, Addis Ababa, Ethiopia.

EK: Assistant professor of obstetrics and gynecology (MD), Addis Ababa University, Addis Ababa, Ethiopia.

GM: Associate Professor of Epidemiology and Biostatistics, (PhD), Aklilu Lemma Institute of Pathobiology, Addis Ababa University, Addis Ababa, Ethiopia.

AF: Associate Professor of Psychiatry (MD, PhD, MRCPsych), Addis Ababa University, Addis Ababa, Ethiopia. He is also MRC African Research Leader.

\section{Competing interests}

The authors declare that they have no competing interests.

\section{Consent for publication}

\section{Not applicable.}

\section{Ethics approval and consent to participate}

Ethical clearance (ref. number: 024/14/psy dated 23/03/14) was obtained from the Institutional Review Board of the College of Health Sciences, Addis Ababa University. Informed consent was obtained from all participants after explanation about the study. A total of 155 women (105 with suicidal ideation and 50 with symptoms of major depression as assessed by the PHQ-9) were referred to the nearby health center where mental health services were available.

\section{Author details}

'Department of Psychiatry, College of Health Sciences School of Medicine, Addis Ababa University, Addis Ababa, Ethiopia. ${ }^{2}$ Department of Psychology, College of Social Science and Humanities, Debre Markos University, Debre Markos, Ethiopia. ${ }^{3}$ Global Mental Health, Centre for Global Mental Health, Health Services and Population Research Department, Institute of Psychiatry, King's College London, London, UK. ${ }^{4}$ Department of Obstetrics and Gynecology, College of Health Sciences, Addis Ababa University, Addis Ababa, Ethiopia. ${ }^{5}$ Aklilu Lemma Institute of Pathobiology, Addis Ababa University, Addis Ababa, Ethiopia. ${ }^{6}$ Center for Innovative Drug Development and Therapeutic Trials for Africa (CDT-Africa), Addis Ababa University, Addis Ababa, Ethiopia. ${ }^{7}$ Department of Psychological Medicine, Centre for Affective Disorders, Institute of Psychiatry, Psychology and Neuroscience, King's College London, London, UK.

\section{Received: 24 December 2015 Accepted: 4 October 2016 \\ Published online: 10 October 2016}

\section{References}

1. WHO. Trends in Maternal Mortality: 1990 to 2010. Geneva: WHO, UNICEF, UNFPA and The World Bank estimates; 2012.

2. Hogan M, Foreman K, Naghavi M, Ahn S, Wang M, Makela S, et al. Maternal Mortality for 181 Countries, 1980-2008: A systematic analysis of progress towards Millenium Development Goal 5 (MDG-5). Lancet. 2010;375(9726):1609-23.

3. Aktar S. Health Care Seeking Behavior for safe motherhood: Findings from Rural Bangladesh. Bangladesh e-J Soc. 2012;9(2):57-70.

4. Babalola S, Fatusi F. Determinants of use of maternal health services in Nigeria-looking beyond individual and household factors. BMC Pregnancy Childbirth. 2009;9:43.

5. CSA. Ethiopia Demographic and Health Survey. Addis Ababa: ICF International; 2011.

6. Regassa N. Antenatal and postnatal care service utilization in southern Ethiopia: a population-based study. Afr Health Sci. 2011;11(3):390-7.

7. Simkhada B, Teijlingen E, Porter M, Simkhada P. Factors affecting the utilization of antenatal care in developing countries: systematic review of the literature. J Adv Nurs. 2007;6(13):244-60.

8. Abebe F. Factors associated with home delivery in Bahirdar, Ethiopia: A case control study. BMC Res Notes. 2012;5:653.

9. Worku A, Fantahun M. Factors affecting utilization of skilled maternal care in Northwest Ethiopia: a multilevel analysis. BMC Int Health Hum Rights. 2013;13:20.

10. Worku A, Yalew A, Afework M. Maternal Complications and Women's Behavior in Seeking Care from Skilled Providers in North Gondar, Ethiopia. PLoS One. 2013;8(3):e60171.

11. Abera $M, G /$ mariam $A$, Belachew $T$. Predictors of safe deliery serice utilizion in Arsi Zone, South-East Ethiopia. Ethiop J Health Sci. 2011; 21(Special Issue):95-106.

12. Tefera A, Alemu FM, Woldeyohannes SM. Institutional delivery service utilization and associated factors among mothers who gave birth in the last 12 months in Sekela District, North West of Ethiopia: A community-based cross sectional study. BMC Pregnancy Childbirth. 2012;12:74.

13. Fisher J, de Mello MC, Izutsu T, Tran T. The Ha Noi Expert Statement: Recognition of Maternal Mental Health in Resource Constrained is essential for achieveing the milinium development goals. Int J Ment Heal Syst. 2011;5:2.

14. CSA. Ethiopia: Improved Capacity of Training Institutions for Health Workers. Addis Ababa: Ethiopian society of population studies; 2005.

15. Mersha A, Jira C, Demessie S. Community based study on maternal mortality in Jimma town, south western Ethiopia. Indian J Public Health. 1996;40(2):30-4

16. Garomssa H, Dwivedi A. Maternal mortality in Ambo Hospital: a five year retrospective review. Ethiop J Reprod Health. 2008;2(1):1-13.

17. Gaym A. Maternal mortality studies in Ethiopia-magnitude, causes and trends. Ethiop Med J. 2009;47(2):95-108.

18. Say L, Chou D, Gemmill A, Tuncalp O, Moller A, Daniels J, et al. Global causes of maternal death: a WHO systematic analysis. Lancet Glob Health. 2014;2(6):323-33.

19. WHO. Health Situation Analysis in the African Region: Atlas of Health Statistics. In: Africa WRof, editor. 2011.

20. Ahmed F, Moussa K, Petterson K, Asamoah B. Assessing knowledge, attitude, and practice of emergency contraception: a cross-sectional study among Ethiopian undergraduate female students. BMC Public Health. 2012;12:110

21. Bradley E, Byam P, Alpern R, Thompson J, Zerihun A, Abeb Y, et al. A Systems Approach to Improving Rural Care in Ethiopia. PLoS ONE. 2012; 7(4):e35042

22. Farnes C, Beckstrand RL, Callister LC. Help-Seeking Behaviors in Childbearing women in Ghana, West Africa. Int Nurs Rev. 2011;58:491-7.

23. Berhan Y, Berhan A. Review of Maternal Mortality in Ethiopia: A story of the past 30 years. Ethiop J Health Sci. 2014;(Speicla Issue):3-14. 
24. Abdulahi $H$, Mariam DH, Kebede D. Burden of Disease Analysis in Rural Ethiopia. Ethiop Med J. 2001;39:271-81.

25. Andersson L, Sundstrom-Poromaa I, Wulff M, Astrom M, Bixo M. Implications of antenatal depression and anxiety for obstetric outcome. Obstet Gynecol. 2004;104(3):467-76.

26. Dayan J, Creveuil C, Herlicoviez M, Herbel C, Baranger E, Savoye C, et al. Role of anxiety and depression in the onset of spontaneous preterm labor. Am J Epidemiol. 2002;155(4):293-301.

27. Grigoriadis S, VonderPorten EH, Mamisashvili L, Tomlinson G, Dennis CL, et al. The Impact of Maternal Depression during pregnancy on Perinatal Outcomes: A systematic Review and Meta-analysis. J Clin Psychiatry. 2013; 74(4):e321-41.

28. Grote N, Bridge J, Gavin A, Melville J, lyengar S, Katon W. A Meta-analysis of Depression During Pregnancy and the Risk of Preterm Birth, Low Birth Weight, and Intrauterine Growth Restriction. Arch Gen Psychiatry. 2010; 67(10):1012-24.

29. Hanlon C, Medihin G, Alem A, Tesfaye F, Lakew Z, Worku B. Impact of antenatal common mental disorders upon perinatal outcomes in Ethiopia: The P-MaMiE Population-based cohort study. Trop Med Int Health. 2008; 14(2):156-66.

30. Senturk V, Hanlon C, Medihin G, Dewey M, Araya M, Alem A, Prince M, Stewart R. Impact of Perinatal somatic and common mental disorder symptoms on functioning on Ethiopian Women: The P-MaMiE population based cohort study. J Affect Disord. 2012;136:340-3349.

31. Bindt C, Appiah-Poku J, Te Bonle M, Schoppen S, Feldt T, Barkmann C, et al. Antepartum depression and anxiety associated with disability in African women: cross-sectional results from the CDS study in Ghana and Cote d'Ivoire. PLoS One. 2012;7(10):e48396.

32. Dibaba $Y$, Fantahun $M$, Hindin M. The association of unwanted pregnancy and social support with depressive symptoms in pregnancy: evidence from rural Southwestern Ethiopia. BMC Pregnancy Childbirth. 2013;13:135.

33. Fisher J, Tran T, La B, Kriitma K, Rossenthal D, Tran T. Common Perinatal Mental disorders in Northern Viet Nam: Community Prevalence and Health Care Use. Bull World Health Organ. 2010;88:737-45.

34. Medihin G, Hanlon C, Dewey M, Alem A, Tesfaye F, Lakew Z, et al. The effect of Maternal common mental disorders on infant undernutrition in Butajira, Ethiopa: P-MaMiE study. BMC Psychiatry. 2010;10:32.

35. Situala S, Shakya R, Shyangwa P. Depression during Pregnancy in a Tertiary Care Center of Eastern Nepal. J Nepal Med Assoc. 2008;47(171):128-31.

36. Lancaster C, Gold K, Flynn H, Yoo H, et al. Risk factors for depressive symptoms during pregnancy: a systematic review. Am J Obstet Gynecol. 2010;202(1):5-14.

37. WHO. Millenium Development Goal 5: Improving maternal health. Geneva: Department of Mental Health and Substance Abuse; 2008.

38. Bonari L, Pinto N, Einarson A, Steinereir M, Koren G. Perinatal Risks of Untreated Depression During Pregnancy. Can J Psychiatry. 2004:49(11):726-35.

39. Rahman A, Bunn J, Lovel H, Creed F. Association between antenatal depression and low birthweight in a developing country. Acta Psychiatr Scand. 2007;115:481-6.

40. Stein A, Pearson R, Goodman S, Rapa E, Rahman A, McCallum M, et al. Effects of perinatal mental disorders on the fetus and child. Lancet. 2014; 384:1800-19.

41. Magriples U, Kershaw T, Rising S, Massey Z, Ickovics J. Prenatal health care beyond the obstetrics service: Utilization and predictors of unscheduled care. Am J Obstet Gynecol. 2008;198(1):75.e1-e7.

42. Chandler D. Late Entry into Prenatal care in a Rural Setting. J Midwifery Womens Health. 2002;47:28-34.

43. Kim H, Mandell M, Crandall C, Kuskowski M, Dieperink B, Buchberger R. Antenatal psychiatric illness and adequacy of prenatal care in an ethnically diverse inner-city obstetric population. Arch Womens Ment Health. 2006;9(2):103-7.

44. Weobong B, Asbroek A, Soremekun S, Manu A, Owusu-Agyei S, Prince M, et al. Association of Antenatal Depression with Adverse Consequences for the Mother and Newborn in Rural Ghana: Findings from the DON Population-Based Cohort Study. PLoS ONE. 2014;9(12):e116333.

45. Baron E, Hanlon C, Mall S, Honikman S, Breuer E, Kathree T, et al. Mental health in primary care in five low and middle income countries: a situtational analysis. BMC Health Serv Res. 2016;16:53. doi:10.1186/s12913-016-1291-z

46. CSA. Statistical Abstracts (2011/2012): Annual Statistical Reports. 2011.
47. Fekadu A, Medhin G, Selamu M, Hailemariam M, Alem A, Giorgis TW, et al. Population level mental distress in rural Ethiopia. BMC Psychiatry. 2014;14:194.

48. CSA. The 2007 Poulation and Housing Census of Ethiopia: Resullts for SNNPR. In: Statistical Report on population Size and Characterstics. 2010. Part I.

49. Selamu M, Asher L, Hanlon C, Medihin G, Hailemariam M, Patel V, et al. Beyond the Biomedical: Community resources for mental health care in rural Ethiopia. PLoS ONE. 2015;10(5):e0126666.

50. Kotelchuck M. The Adequacy of Prenatal Care Utilization Index: Its US Distribution and Association with Low Birthweight. Public Health Brief. 1994;9(9).

51. Kroenke K, Spitzer R, Wiliams J. Validity of a Brief Depression Severity Measure. J Gen Intern Med. 2001;16:606-13.

52. Gelaye B, Williams M, Lemma S, Deyessa N, Bahretibeb Y, Shibre T, et al. Validity of the patient health questionnaire-9 for depression screening and diagnosis in East Africa. Psychiatry Res. 2013;210(2):653-61.

53. Hanlon C, Medihin G, Alem A, Araya M, Abdulahi A, Tesfaye M. Measuring Common Mental Disorders in Women in Ethiopia: Reliability and construct Validity of Comprehensive Psychopathological rating Scale. Soc Psychiatry Psychiaric Epidemiol. 2008;43:653-9.

54. Rabin R, Jennings J, Campbell J, Bair-Merritt M. Intimate Partner Violence Screening Tools. Am J Prev Med. 2009:36(5):439-45.

55. Zink T, Levin L, Putnam F, Beckstrom A. Accuracy of Five Domestic Violence Screening Questions With Nongraphic Language. Clin Pediatr. 2007;46(2):127-34.

56. Boen $\mathrm{H}$. Characteristics of senior centre users-and the impact of a group programme on social support and late-life depression. Norsk Epidemiologi. 2012;22(2):261-9.

57. Brugha TS, Cragg D. The List of Threatening Experiences: the reliability and validity of a brief life events questionnaire. Acta Psychiatr Scand. 1990;82(1):77-81.

58. Fotso J, Mukiira C. Perceived quality of and access to care among poor urban women in Kenya and their utilization of delivery care: harnessing the potential of private clinics? Health Policy Plan. 2011;1-11.

59. Hartley M, Tomlinson M, Greco E, Comulada S, Stewart J, Roux J, Mbewu N, Rotheram-Borus N. Depressed mood in pregnancy: Prevalence and correlates in two Cape Town peri-urban settlements. Reprod Health J. 2011:8:9.

60. Anselmi L, Barros F, Minten G, Gigante D, Horta B, Victora C. Prevalence and early deteminants of common mental disorders in the 1982 birth cohort, Pelotas, South Brazil. Rev Saude Publica. 2008;42(12):26-33.

61. Alder J, Fink N, Urech C, Hosli I, Bitzer J. Identification of antenatal depression in obstetric care. Arch Gynecol Obstet. 2011;284(6):1403-9. Epub 2011/03/23. eng.

62. Katon W. Epidemiology and treatment of depression in patients with chronic medical illness. Dialogues Clin Neurosci. 2011;13(1):7-23.

63. DiMatteo R, Lepper H, Croghan T. Depression Is a Risk Factor for Noncompliance With Medical Treatment Meta-analysis of the Effects of Anxiety and Depression on Patient Adherence. Arch Intern Med. 2000;160:2101-7.

64. Arthur E. Wealth and antenatal care use: implications for maternal health care utilisation in Ghana. Heal Econ Rev. 2012;2:14.

65. Webster J, Pritchard M, Linnane J, Roberts J, Hinson J, Starrenburg S. Postnatal depression: use of health services and satisfaction with health-care providers. J Qual Clin Pract. 2001;21(4):144-8.

66. Zuckerman B, Amaro H, Bauchner H, Cabral H. Depressive symptoms during pregnancy: relationship to poor health behaviors. Am J Obstet Gynecol. 1989:160(5):1107-11.

67. Airaksinen E, Larsson M, Forsell L. Cognitive functions in depressive disorders: evidence from a population-based study. Psychol Med. 2004;34:83-91.

68. Nauatin M, Mitchel P, Goodwin G. Cognitive Deficits in Depression: A review article. BJP. 2001;178:200-6.

69. Hanlon C, Whitley R, Wondimagegn D, Alem A, Prince M. Between life and death: exploring the socio-cultural aspect of antenatal mental distress in rural Ethiopia. Arch Womens Ment Health. 2010;13(5):385-93.

70. Stewart R, Umar E, Gleadow-Ware S, Creed F, Bristow K. Perinatal distress and depression in Malawi: an exploratory qualitative study of stressors, supports and symptoms. Arch Womens Ment Health. 2015:18:177-85.

71. Mwape L, McGuiness T, Dixey R, Johnson S. Socio-cultural factors surounding Mental distress during the perinatal period in Zambia: a qualitative investigation. Int J Ment Health Syst. 2012:6(12):1-10.

72. Dennis C. Influence of depressive symptomatology on maternal health service utilization and general health. Arch Womens Ment Health. 2004;7:183-91.

73. Mogga S, Prince M, Alem A, Kebede D, Stewart R, Glozier N, et al. Outcome Of major Depression In Ethiopia Population-Based Study. Br J Psychiatry. 2006;189:241-6. 